\title{
Poética do caos: a conquista de Babel
}

Arnaldo Rosa Vianna Neto

Recebido em 01/06/2011 - Aprovado em 27/08/2011

\section{Resumo}

Do conflito entre as lógicas ocidental e crioula surgem debates sobre o uso da lingua francesa por escritores de países francófonos. Patrick Chamoiseau discute o tema em sua obra, onde a palavra poética aparece como um "lugar" fora do tempo e do espaço, no qual todas as linguas francesas se encontram.

Palavras-chave: crioulidade; identidade; escrita; oralidade. 
Et plus que jamais, l'écrivain créole assis devant sa feuille perçoit à quel point, sur cette tracée opaque située entre l'oral et l'écrit, il doit abandonner une bonne part de sa raison, non pour déraisonner mais pour se faire voyant, inventeur de langages, annonciateur d'un autre monde. Je veux dire qu'il doit se faire Poète. ${ }^{1}$

Patrick Chamoiseau

\begin{abstract}
"E mais do que nunca, o escritor crioulo sentado diante de sua folha de papel, percebe a que ponto, sobre este traçado opaco situado entre o oral e o escrito, ele deve abandonar boa parte de sua razão, não para desarrazoar, mas para se fazer vidente, inventor de linguagens, anunciador de um outro mundo. Quero dizer que ele deve se fazer Poeta." (Tradução de nossa autoria)

2 Filhotes de tigre não nascem sem garras. (Patrick Chamoiseau, 1986, p. 101)
\end{abstract}

3 No verbete crioulo em dicionários de línguas neolatinas encontra-se "uma multiplicidade de registros no percurso conceitual do termo. Egresso do latim criare com o sentido de educar, o termo identificava os que nasciam e eram educados nas Américas sem ser originários delas [...]. Alguns dicionários franceses registram a ocorrência do termo apenas no século XIX, tornando seu uso restrito à linhagem de colonos brancos chamados de békés nas Antilhas. [...] O dicionário enciclopédico Le Petit Larousse refere crioulo como pessoa de ascendência européia nascida nas antigas colônias francesas de plantação, como Antilhas, Guianas, Reunião etc, e também, como o dialeto surgido por ocasião do tráfico de escravos africanos entre os séculos XVI e XIX, tornando-se a língua materna dos descendentes desses escravos. (cf. Magdala França Vianna, Crioulização e Crioulidade, p. 103-4, em Conceitos de Literatura e Cultura, 2005.)

\section{Les petits du tigre ne naissent pas sans griffes ${ }^{2}$}

Os escritos teóricos sobre a produção cultural do Caribe não têm resolvido o problema conceitual de definição dos processos de ressignificação identitária próprios da região cuja situação de insularidade favorece o trânsito de uma multiplicidade de línguas e paradigmas culturais diversos movendo-se em dinâmica de reorganização constante. Nossa análise dos discursos sobre a produção literária antilhana dos últimos vinte anos do século XX parte da premissa de que o pensamento em torno da cultura e, em particular, da literatura constitui um lugar privilegiado para o estudo das complexas relações étnicas e culturais, difíceis de reduzir em oposições binárias como colonizador / colonizado, cultura dominante / cultura dominada.

O malaise ("mal-estar") do homem créole", nascido e criado no Caribe, é registrado por muitos escritores que inscrevem em suas obras a marca linguística da diferença. As interrogações que advêm da condição do ser crioulo decorrem da incerteza do pertencimento sócio-político-cultural e seu inevitável condicionamento existencial. Nesse âmbito, situando-se o "lugar" de enunciação do escritor entre diferentes culturas, a prática do fouillement, a "escavação" teórica dos conceitos que constituem as formações discursivas crioulas e os imaginários dominantes torna-se um ato obrigatório para que se torne possível articular a superposição e a inclusão de diferentes culturas que convivem em permanente tensão. Entretanto, a questão da autoria, que parece ser primordial para a compreensão das dinâmicas em curso na produção literária antilhana do fim do século $X X$, do modo como é analisada pelos próprios escritores, configura um paradoxo expresso da seguinte maneira: se a presença do autor é necessária na medida em que só ele pode dar corpo a uma comunidade antilhana, ou seja, fundar uma comunidade em torno da história e da memória na prática de um jogo social e literário, é o próprio ato de escrever que o afasta da identidade de créole e de sua língua materna.

$\mathrm{O}$ atual debate sobre os conceitos de identidade cultural tem como referência as pesquisas que destacam a importância da revisão crítica da dicotomia entre língua materna e língua do Outro. A relação entre a epistemologia das questões de língua e linguagem - e entre o que elas carreiam de ético e político - 
remete às fronteiras (moventes) das identidades linguísticas e culturais em que se inscrevem os imaginários das línguas. Entendendo-se que "a nação não é apenas uma entidade política, mas algo que produz sentidos - um sistema de representação cultural" (HALL, 1999, p. 48.), acrescenta-se à noção de pátria um conteúdo não apenas político, mas também cultural e linguístico. Ele corresponde não a uma entidade política, mas a um vasto espaço geográfico e cultural onde o francês de referência, submetido a diversos tipos de contatos linguísticos, mostra fenômenos de mestiçagem cuja natureza e importância variam segundo o contexto linguístico.

\section{Nós e o(s) Outro(s)}

O alterismo, definido por Kwame Appiah como a "celebração de si mesmo como o Outro" (1997, p. 217), aponta as tensões criadas pela retórica bipolar ocidental de centro e periferia, identidade e diferença como responsáveis pelos mecanismos classificatórios e/ou discriminatórios de sistemas políticos baseados em relações conflituais vigentes nos processos de colonização e descolonização e, ainda, em situações pós-coloniais específicas. $\mathrm{O}$ lugar da alteridade, uma subversão, pois, da metafísica ocidental, funciona como símbolo e não signo da presença.

A construção de um paradigma regional em sociedades caracterizadas pela heterogeneidade ethoetnocultural, como as do Caribe insular, tem sido marcada pela busca de uma identidade crioula, ou seja, a incorporação de elementos emblemáticos que funcionam como articuladores da série de diferenças culturais, religiosas, linguísticas e econômicas. O movimento da Antilhanidade assinado por Édouard Glissant é uma referência do processo de crioulização no espaço antilhano, uma territorialização do movimento no Caribe, após o desvio africano da Negritude de Aimé Césaire, uma construção unidimensional, mas necessária à montagem da identidade do homem multidimensional crioulo. Patrick Chamoiseau, Raphaël Confiant et Jean Bernabé, escritores e linguista antilhanos, autores do Éloge de la Créolité (1989), ensaio que é um verdadeiro manifesto, recusam a pretensão ocidental à universalidade, ou seja, os paradigmas a partir dos quais se pode dimensionar a humanidade e apontam a

4 "Nós vimos o mundo valores ocidentais e nossa essência foi 'exotizada' pela visão francesa que tivemos que adotar. Condição terrível essa de perceber sua arquitetura interior, seu mundo, os instantes de seus dias, seus próprios valores com o olhar do Outro". (Tradução de nossa autoria) questão da elaboração de uma identidade crioula como problema essencial. O Elogio da Crioulidade denuncia a "exotização" do Nós antilhano pelo olhar do Outro:

Nous avons vu le monde à travers le filtre des valeurs occidentales, et notre fondement s'est trouvé 'exotisé' par la vision française que nous avons dû adopter. Condition terrible que celle de percevoir son architecture intérieure, son monde, les instants de ses jours, ses valeurs propres, avec le regard de l'Autre. ${ }^{4}(1989$, p. 14) 
5 Édouard Glissant referenda o pensamento do antropólogo brasileiro Darcy Ribeiro (1978), que, como outros pesquisadores latino-americanos, defende uma nova cartografia das Américas baseada no conceito de região definida pela mobilidade do processo de crioulização. Em Introduction à une Poétique du Divers (1996), Glissant descreve a existência de três Américas que se interpenetram, muitas vezes de maneira indissociável: a Meso-América dos ameríndios; a Euro-América, constituída pelo Québec, Canadá, Estados-Unidos e uma parte do Chile e da Argentina, que preservaram construções ethoetnoculturais de seus países de origem; e a Neo-América, definida por ele como a América da crioulização, herdeira das civilizações egressas do sistema de plantação e povoamento, ou seja, a América constituída pelo Caribe, o nordeste do Brasil, Guianas e Curaçao, a costa caribenha da Venezuela e da Colômbia e uma grande parte da América Central, do México e do sul dos Estados-Unidos, particularmente a Luisiana. (cf. Id, ibid, p. 110)

6 "As Américas se arquipelizam, elas se constituem em regiões para além das fronteiras nacionais. E eu acredito que é preciso recuperar, em sua dignidade, o termo região. A Europa se arquipeliza. As regiões linguísticas, as regiões culturais, para além das barreiras das nações, são ilhas, mas ilhas abertas, e esta é sua principal condição de sobrevida". (Tradução de nossa autoria)

A reescrita da oralidade tradicional se articula a uma forma de resistência contínua e característica do sistema colonial de plantações. O que se chama de oralidade tradicional corresponde, no Haiti, a oraliture, ou seja, um corpus extenso e variado
A Crioulidade não se define como um movimento fechado em torno das civilizações do Caribe, mas como fundamento do ser crioulo, vetor estético de sua consciência e do mundo, orientado para a reorganização do objeto estético crioulo sem a mediação do Outro europeu como terapia para a recuperação do trauma identitário. É a construção de um existencial crioulo, uma inteligência crioula em um novo contexto histórico. Em conferência pronunciada no Festival caribenho Seine-SaintDenis, em 22 de maio de 1988, Chamoiseau expõe alguns vetores do pensamento da Crioulidade, como a complexidade cultural aberta e complexa, a diversidade permanente, ou seja, a metamorfose contínua e antropofágica, a crioulização como fenômeno cultural transversal universal. Segundo os autores do Éloge, na França, crioulo (créole) significa, na maioria das vezes, língua crioula, o que explica uma tendência para a redução do conceito a uma simples defesa da língua que é, entretanto, apenas um dos elementos de "um combate bem mais amplo, ou seja, o da identidade múltipla" que supõe a partilha de identidades. O escritor e pensador antilhano Édouard Glissant, definindo o Caribe como região ${ }^{5}$ cultural, enfatiza que o sentido de sua historicidade, no caso especial das Antilhas francesas, implica uma necessária parceria intercultural entre as sociedades francocrioulofônicas:

Les Amériques s'archipélisent, elles se constituent en régions par-dessus les frontières nationales. Et je crois que c'est un terme qu'il faut rétablir dans sa dignité, le terme de région. L'Europe s'archipélise. Les régions linguistiques, les régions culturelles, par-delà les barrières des nations, sont des îles, mais des îles ouvertes, c'est leur principale condition de survie. $^{6}$ (1996, p. 44)

Essa episteme é o lugar de realização de uma polifonia móvel que referenda a ocorrência de construções sincréticas caracterizadas pela justaposição de multiplicidades culturais na busca de uma nova ordem discursiva descentralizada e sem genealogias. A assunção da identidade passa, necessariamente, pela interrogação da alteridade (Nós e os Outros), das vozes que se elevam de um espaço histórico e de um ethos social múltiplo e heterogêneo. Ao fazê-lo, o texto literário transforma a língua, incorporando a oralidade à escritura. ${ }^{7}$ Lida em sua polifonia, em uma relação de intervocalidade, tal como concebeu o antropólogo e medievalista francês Paul Zumthor, a diferença se acentua. Segundo ele, ocorre, nas mediações da "tradição", o domínio da variante e sua consequente movência, a partir da qual "se pode ouvir uma rede vocal imensamente extensa e coesa [...] que seria o murmúrio dos séculos; do mesmo modo, pode-se também ouvir, isolada, a própria voz do intérprete" (1993, p. 145). A assimilação do "mesmo" procede da ação contínua e interrupta das variantes, combina reprodução e mudança, contrariamente 
de formas tradicionais de origem indígena, africana ou européia, adaptadas ao universo americano das plantações e transmitidas oralmente. Na sociedade colonial e escravagista, essas formas tinham a função de permitir a circulação da palavra e do saber. Elas eram, portanto, o suporte e a expressão da coletividade e seu imaginário. A oralidade comporta vários gêneros: contos, provérbios, adivinhas, cantos profanos e rituais, entre outros.

8 "a marca secreta, impossível e (des)velada" (Tradução de nossa autoria) à transmissão puramente escrita, ou seja, a "movência", escreve Zumthor, é criação contínua (1993, p. 145).

$\mathrm{Na}$ literatura antilhana, o registro escrito de expressões orais (ou os textos escritos com a intenção de resgatar, preservar e incorporar ao texto literário a representação da oralidade), instiga à análise da polifonia na recepção dos destinatários do texto, quaisquer que sejam as modalidades e o estilo de desempenho que se manifesta exclusivamente pela voz. Segundo Zumthor, a intervocalidade se desdobra simultaneamente em três espaços: aquele em que cada discurso se define como lugar e transformação (mediante e em uma palavra concreta) de enunciados vindos de outra parte; o de uma audição, hic et nunc, regida por um código mais ou menos formalizado, mas sempre, de algum modo, incompleto e entreaberto ao imprevisível; enfim, o espaço textual interno, gerado pelas relações que aí se constituem (1993, p. 145). Além disso, diz ainda Zumthor, é preciso observar a margem de liberdade deixada pelos textos à voz de cada um de seus intérpretes, considerando-se que a imprecisão da recepção, ao invés de separar, promove a união com outros textos (1993, p. 147).

A relação entre oralidade e escrita não é um fenômeno e/ ou uma prática diglóssica unicamente antilhanos, mas de toda criação latino-americana. É evidente que a inserção de palavras crioulas ou de expressões populares na escrita, com explicações no pé-de-página ou em glossário no fim do livro, não implica forçosamente uma reescrita da oralidade tradicional. Não se trata de reproduzir simplesmente a linguagem oral cotidiana, nem de adotar uma sintaxe próxima do discurso descontínuo registrado no magnétophone, mas de escrever adotando a rítmica falada, o "ressassement" (a repetição) e o espírito da oralidade, ou seja, tomando de empréstimo o estilo do conteur, o contador popular. O problema das formas orais (conto, canto, adivinhações, provérbios, comptines etc) deve se ligar à sua função na coletividade e a um certo contexto. É importante compreender que essas formas não pertencem à língua, mas à linguagem e à metalinguagem de uma situação. Sua (re)criação, oriunda de um ato específico de "enunciação transpessoal", é uma atividade de linguagem, um discurso cujo referente é o enunciador anônimo e o (re)enunciador (letrado) em relação a uma situação.

Nas Antilhas francesas, todo texto escrito em francês é escrito na língua do Outro. A língua materna da Martinica, de Guadalupe e da Guiana francesa não é uma língua autenticamente oral (o que a distingue, por exemplo, das línguas étnicas africanas), o que ela traz é "la marque secrète, impossible et repérable" 8 do escrito, como observa Glissant (1981, p. 22). O leitor não crioulofono deve aceitar a existência de uma zona de opacidade que não poderá ser perfeitamente avaliada e que revela um jogo secreto com o créole. É interessante interrogar o 
9 Colonos brancos de origem européia.

10 " $[. .$.$] eu sou de um país$ onde se faz a passagem de uma literatura oral tradicional violentada, a uma literatura escrita, não tradicional, também violentada. Minha linguagem tenta se construir no limite do escrever e do falar; assinalar tal passagem - o que é certamente bem árido em toda abordagem literária. [...] Eu evoco uma síntese, síntese da sintaxe escrita e da rítmica falada, do 'adquirido' da escrita e do 'reflexo' oral, da solidão da escrita e da participação no cantar comum - síntese que me parece interessante tentar." (Tradução de nossa autoria)

11 Nascido em 1953, na cidade de Fort-de-France, capital da Martinica, Patrick Chamoiseau, escritor, jornalista (editorialista), roteirista de cinema, diplomado em direito e economia social, é educador social no Tribunal para jovens delinquentes de Fort-de-France. Sua obra é composta por autobiografias, contos, ensaios, romances, teatro, roteiros de filmes, como L'exil du roi Béhanzin (1996), Biguine (2004), Passage du milieu (2001), produzidos por Guy Deslaurier, Nord-Plage (2004) e Aliker (2007). Por seu romance Texaco (1992) recebeu o Prix Goncourt de literatura; pela autobiografia Antan d'Enfance (1993), o Prix Carbet; pelo romance Biblique des derniers gestes (2002), o Prix Spécial du Jury RFO. sentido dessa estratégia que consiste em passar pela língua do Outro: um recuo crítico dado pelo exílio; a decifração de um imaginário; um olhar distanciado sobre a cultura de origem, graças ao desvio de uma língua tomada de empréstimo e à exploração dos possíveis da escrita advindos das interdições sociais veiculadas pela língua materna; e o reconhecimento do multilinguismo caribenho são alguns dos itens que se poderia invocar. Há, ainda, uma construção a ser explorada do ponto de vista crítico: o de reconquistar, pelo viés da língua do Outro, um costume em vias de extinção na língua materna, um pacto secreto, base da união da coletividade.

Glissant distingue dois usos do crioulo na Martinica: o crioulo dos békés ${ }^{9}$ e o crioulo dos escravos, depois trabalhadores agrícolas (1981, p. 246-45). O uso popular do crioulo constituía, originalmente, uma espécie de pacto e comportaria um sentido oculto. A "função iniciática" desaparece à medida que o crioulo, não sendo mais uma língua de produção, desenvolvese em língua aberta (a situação difere no Haiti, onde o crioulo continua a ser uma língua de produção no sentido amplo da palavra). Nessa observação de Glissant, considera-se que, nas culturas diglóssicas, uma das funções do texto inspirado nas formas populares é reconquistar, por intermédio do francês, essa dimensão de pacto secreto. Se a oralidade, tal como é definida habitualmente, compreende tudo o que permite a circulação da palavra e do saber, sem escrita, em uma comunidade, os cantos, os ritmos, as danças se revelam como modos de comunicação tão importantes como o discurso. Nas Antilhas francófonas, Édouard Glissant é um dos que mais refletiram e teorizaram sobre a escrita da oralidade tradicional. Em um texto intitulado Le roman des Amériques, ele expõe seu projeto literário:

[...] je suis d'un pays où se fait le passage d'une littérature orale traditionnelle, contrainte, à une littérature écrite, non traditionnelle, tout aussi contrainte. Mon langage tente de se construire à la limite de l'écrire et du parler; de signaler un tel passage - ce qui est certes bien ardu dans toute approche littéraire. [...] J'évoque une synthèse, synthèse de la syntaxe écrite et de la rythmique parlée, de l' 'acquis' de l'écriture et du 'réflexe' oral, de la solitude d'écriture et de la participation au chanter commun - synthèse qui me semble intéressante à tenter ${ }^{10}$. (1981, p. 256)

\section{Poética e ideologia: o marqueur, o conteur, o etnógrafo e o escritor}

Os romances de Édouard Glissant, Maryse Condé, Raphaël Confiant, mas principalmente os de Patrick Chamoiseau ${ }^{11}$, carregados de tensões não resolvidas, convidam o pesquisador a avaliar a questão das condições de surgimento de uma literatura antilhana. É nesse âmbito que se põe em evidência a difícil 
passagem entre o créole e o francês, o oral e o escrito, o conteur e o escritor.

Em uma região em que a história foi "confiscada", parece importante que o narrador e o escritor estabeleçam como conduta de sua prática poética o ato de testemunhar e consignar as histórias (re)encontradas. O autor das Antilhas é habitado por uma contradição: sua ação se divide entre a necessidade de escrever para testemunhar, redefinir a História, recuperar o "nous disjoint" reivindicado por Glissant, e o medo de trair sua crioulidade aceitando escrevê-la em francês.

Se a história das Antilhas é constituída por lacunas, silêncios, rupturas e caos, ela não pode ser objeto de análise de historiadores racionais que privilegiam, classificam e ordenam os fatos históricos. A história antilhana, segundo o Éloge de la Créolité, "não é totalmente acessível aos historiadores". O ato de narrar, opaco e visível torna-se o próprio jogo do texto. Não se trata tanto de contar uma história, mas de perguntar quem conta, como conta, de que ponto de vista, com que autoridade, saber e em que logos. Com Glissant, o narrador não é mais aquele que conta, mas o que reúne. $\mathrm{O}$ narrador de Texaco de Patrick Chamoiseau é igualmente um relayeur de paroles. Entretanto, pode acontecer que ele fracasse ao reler todas as palavras tornando perceptível um chaos que Glissant chama de poé-

12 “Não, escritor não: coletor de palavras, isso muda tudo, inspetor, o escritor é de um outro mundo, ele rumina, elabora ou prospecta, o coletor recusa uma agonia: a da oralitura, ele recolhe e transmite". (Tradução de nossa autoria)

${ }^{13}$ CHAMOISEAU, Patrick et CONFIANT, Raphaël. Lettres Créoles, tracées antillaises et continentales de la littérature. Martinique, Guyane, Guadeloupe, Haïti, 1635-1975. Paris: Éditions Hatier, 1991. Também Édouard Glissant escreve, em seu Discours Antillais, que o tambor é uma "linguagem organizada em discurso". Nas Antilhas, o tambor é solitário, ou serve como acompanhamento. A orquestra de tambores, característica da cultura africana, não sobreviveu nas Antilhas, onde sua manifestação é rara. O que restou como memória da orquestra de tambores foi o gros-ka, o tambor camponês antilhano. tico. A originalidade de Chamoiseau está na invenção de sua língua(gem) de escritor, na qual se registram criações lexicais contínuas que incorporam ao francês as construções lexicais e as cadências crioulas. Sua linhagem é a de François Villon, Faulkner, Rabelais, Joyce, Saint-John Perse e a dos contadores (conteurs) de histórias crioulos.

Desde sua estréia em literatura, com a peça Manman Dlo contre la fée Carabosse (1981), classificada como théâtre conté (teatro contado), Chamoiseau desenvolve em sua obra uma escrita original da oralidade crioula. Em seus romances, a figura do autor - lugar de contradições múltiplas tanto no plano literário como no plano social, é suspeita. Sua recusa do estatuto de escritor, ao adotar o aparato etnográfico de pesquisa para coletar as formas do viver e do fazer cotidianos do povo da Martinica, longe de ser gratuita: "Non, pas écrivain: marqueur de paroles, ça change tout, inspéctère, l'écrivain est d'un autre monde, il rumine, élabore ou prospecte, le marqueur refuse une agonie: celle de l'oraliture, il recueille et transmet"12 (1989, p. 159) -, é uma estratégia para a apropriação política e literária do termo que, em créole, tem um significado polissêmico (o de enquêteur - entrevistador que toma notas e/ou grava, recolhendo e escrevendo as memórias dispersas; o de prospecteur - transmissor da memória para o futuro; o de tambouyé - o tamborineiro que faz o solo dos tambours- $k a^{13}$, no sentido de marquer como ritmar, marcar o ritmo.). Assim, Chamoiseau não só realiza literariamente 
o prazer estético do jogo com o som da oralidade (o vocal) e a polissemia vocabular, a carga semântica incorporada por superposição e incorporação de culturas, mas também expõe a prática de sua ideologia política, visível na produção de um texto crítico em que se inscreve uma nova ordem (como memória do futuro), ou outro logos de poder onde se reconhece o ato inaugural da identidade crioula: a assinatura (como sujeito) de sua(s) própria(s) $\mathrm{h}(\mathrm{H})$ istória(s). As narrativas de Chamoiseau são compostas por "pequenas histórias" do cotidiano, inscritas à margem do texto oficial, nas quais permanecem fragmentos culturais dispersos em circulação no texto oral ao lado da "grande História" da Martinica, como, por exemplo, a erupção da Montagne Pelée em Texaco (1992) e à Segunda Guerra Mundial em Chronique des sept misères (1986).

A metodologia empregada na construção dos romances fundamenta-se no registro da complexidade do processo da memória e da interpretação das fontes orais. Recebendo a pesquisa histórica a colaboração de historiadores orais, pela coleta da tradição oral popular registrada em palavras faladas e transmitidas pela maioria desconhecida do povo, incorpora-se a evidência oral na história social e confere-se à história oral, às fontes orais, a função social da história dentro de um contexto determinado. O trabalho do escritor é, pois, o de recolher essas memórias e arquivá-las no texto escrito para que não desapareçam definitivamente. Questiona-se, assim, a natureza e o significado da "história oficial". O "contar" a História pelo viés das histórias do cotidiano revitaliza o sentido dos kont créoles (os contos orais crioulos) na elaboração do texto (sintagma e paradigma) de Chamoiseau. As narrativas se constroem em uma

14 Chamoiseau tem no nome o signo do Cam (Cham) bíblico (Sem, Cam e Jafet), e o significado de pássaro (oiseau) como símbolo do canto, da oralidade quase perdida do "povo dos mercados" de Fort-de-France.

15 "eu passei toda a estação das pitombas a traduzir o conjunto em um monte de páginas, turbilhonantes e ilegíveis. Claro, amigos, que eu resolvi extrair de tudo aquilo uma versão reduzida, organizada, escrita, uma espécie de reconstituição daquilo que o Mestre foi naquela noite: estava claro de agora em diante que sua palavra, sua verdadeira palavra, toda sua palavra, estava perdida para todos - e para sempre." (Tradução de nossa autoria) rítmica própria dos kont, na qual se apreendem sons como os dos mercados de Fort-de-France ${ }^{14}$ em Chronique des sept misères (1986) e os do tambor, o gros-ka, em Solibo Magnifique (1989), quando "as mãos suplementares dos tamborineiros" (os tambouriers de cricracks) convocam os mésié-zé-dames de la compagnie ("senhores e senhoras da companhia") para ouvir os kont, respondendo ao conteur com as expressões é-crik! é-crack. O escritor, ao lado da compagnie, nos mercados ou na Savane sob os tamarineiros, anota ou grava os contos para a transmissão escrita (a oralidade incorporada à escrita) das memórias futuras. $\mathrm{O}$ autor ganha também o estatuto de conteur, contador das histórias anotadas, inscrevendo-se nelas como suplemento:

[...] je passais toute la saison des quénettes à traduire l'ensemble sur tout un lot de pages, tourbillonantes et illisibles. Si bien, amis, que je me résolus à en extraire une version réduite, organisée, écrite, une sorte d'erzatz de ce qu'avait été le Maître cette nuit-là: il était clair désormais que sa parole, sa vraie parole, toute sa parole, était perdue pour tous - et à jamais..$^{15}(1989$, p. 211) 
Evidentemente, o leitor não duvida de que se encontra na presença de um verdadeiro texto literário, apesar das astuciosas posturas do escritor em relação não só à autoria do texto, mas também ao papel e ao estatuto de escritor, ou seja, a intenção de dar visibilidade às contradições de sua ars poetica: a representação do autor e sua função social (entre o personagem do escritor e o escritor real), a ficção como testemunho. Chamoiseau descreve as contradições da sociedade martiniquense, entre a cidade e a zona rural, em Chronique des sept misères (1986), misticismo e razão em Solibo Magnifique (1989), modernidade e tradição, estereótipos das relações de gênero entre homens e mulheres na construção da Cidade Crioula em Texaco (1992). Ele constrói uma série de personagens representativas de certa marginalidade, entre eles os dorlis (feiticeiros), os majors (homens fortes nas comunidades), os papa-feuille (raizeiros), os vagabundos e os driveurs (beberrões, bêbados), além de mulheres fortes, como as matador, diablesses, marchandes, viajantes, cozinheiras, matriarcas, soucougnans, cujos destinos se entrecruzam em vários romances e nos quais ele se representa. O marqueur de paroles se quer, antes de tudo, como testemunha de uma sociedade. Por isso ele (re)presenta literariamente as práticas do sociólogo, do etnógrafo, do historiador e do economista, buscando restituir a seu povo a memória coletiva de tradições e histórias em vias de desaparecer.

\section{Políticas da opacidade e lógica do desvio}

Em Le Chaos-Monde, l'Oral et l'Écrit (1994, p. 128), Édouard Glissant conceitua opacidade como negação da "transparência" do modelo universal editado pelo pensamento ocidental. Ele reivindica o direito à opacidade, à descontinuidade, à temporalidade caótica, profetiza o fim do sistema de valores ocidental e seu exercício sobre os povos, conclamando o Ocidente a dividir poética e politicamente esse direito. Sua concepção de política aponta a hegemonia do capital, do "ter", como responsável pela uniformização dos valores que deve ser substituída por uma poética (uma teoria) de investimento na multiplicidade contra o uno universal.

É interessante ressaltar que a descolonização não resultou na desocupação do território ideológico. A filiação e a assimilação dos valores culturais franceses continuaram a legitimar a dominação. A departamentalização (DOM - Département d'Outre Mer) de 1946, ocorrida após a segunda guerra mundial, referendou o processo de francização ou de afrancesamento da Martinica. A emergência da solidariedade e da criatividade durante a guerra, quando a ilha, abandonada à própria sorte pela metrópole precisou inventar formas de sobrevivência, foi anulada pelo plebiscito que resultou na escolha da pátria única e da identidade especular branca e francesa. A terceirização 
da economia, decretada em 1975 pela doutrina de assimilação econômica, institucionalizou o neocolonialismo, que se instalou sutilmente como um substituto social e não promoveu nenhum deslocamento do sistema de valores em que se configurasse um equilíbrio ético-político e estético produtor de uma subjetividade individual e coletiva. A procura de uma pátria existencial, a domicialização em um território interior que, promovendo um universo de referência distante do filtro ocidental que exotizou o estranho à idealização de seu modelo, produzisse a ressingularização étnico-estética do ser desenraizado de uma pátria primordial, buscando a essência atávica para sua referenciação histórica, tornou-se fundamental para a intelligenzia da Martinica.

O movimento de desenraizamento do homem antilhano tem uma dinâmica específica que se caracteriza pela lógica do détour $^{16}$ (desvio). Não se trata mais de um "retorno ao país natal" africano, mas de domicialização americana, caribenha, antilhana, a territorialização insular e continental das sociedades que constituem o que a lógica ocidental nomeia como Terceiro Mundo. Há, portanto, uma nova historicidade, ou uma nova discursividade que tece seu continuum nas Antilhas sistemicamente desde Frantz Fanon e Aimé Césaire e, descontinuamente, no produto da contracultura crioula disseminada na textualidade hegemônica. A organização da Crioulidade, a fundação de sua ordem como inteligência, sensibilidade - sua interioridade, é que a geração de Chamoiseau sistematiza, conceitualiza como uma universalidade, uma dinâmica multidimensional da consciência do ser crioulo planetário, construindo-se como contra-poder marginal.

Glissant situou a Antilhanidade, assim como Fanon situou o Terceiro Mundo, Césaire a Negritude, Gilbert Gratiant a realidade crioula e Chamoiseau a Crioulidade em um movimento processual de recusa da exclusão da discursividade crioula, mestiça, da matriz ocidental produtora de ideologias do uno. É assim que se apaga a ilusão do mito fundador como mito de exclusão do Outro ou, então, de inclusão do Outro pela dominação e para a exploração e se define como lugar de construção da Crioulidade, como uma outra universalidade, o espaço de onde emergiu sua consciência, ou seja, os territórios da colonização: Martinica, Guadalupe, Haiti, Cuba, Guianas, o grande Caribe, Brasil, Américas, Libéria, África do Sul, Argélia, Irlanda, Chipre, Austrália, Índia, China, Indochina, enfim, o Terceiro Mundo crioulo.

\section{A Cidade Crioula}

16 O détour é conceituado por Édouard Glissant no Discours Antillais, p. $28-36$.
A análise de práticas sociais e culturais cotidianas, representadas nas memórias dos imaginários rural e urbano, ao longo do continuum histórico colonial e pós-colonial, revela, 
no referencial discursivo antilhano, ao lado de migrações de representações unitárias e monológicas do logos urbano ocidental, a problematização da alteridade na desconstrução de conceitos ocidentais essencialistas e puristas. Ao lado dessas representações, identifica-se a inscrição discursiva do conflito decorrente do sincretismo policêntrico e polimórfico urbano, desordenado, plural, sem genealogias, errante entre subjetividades etnográficas complexas que caracterizam a alteridade híbrida nas Américas. A ruína do sistema de plantações nas Antilhas determinou a ruptura do continuum cultural crioulo e sua imobilização. A morte do conteur, guardião das matrizes do imaginário colonial e pós-colonial, assinala o nascimento do romance antilhano contemporâneo, lugar de busca da filiação perdida que o escritor propõe reconstruir. No final do século $\mathrm{XX}$, ele tenta fazer renascer a palavra crioula sufocada pela escola republicana. Autores como Édouard Glissant, Raphaël Confiant e Patrick Chamoiseau recusam fazer da literatura crioula um epígono da francesa. Em seu Éloge de la Créolité eles rejeitam o "Parnasse suranné, symbolisme attardé, romantisme de seconde main"17 e se determinam a recuperar a tradição a partir de suas fouilles archéologiques, ${ }^{18}$ metáfora para a escavação atávica da memória e da identidade soterradas no palimpsesto antilhano. Nesse âmbito, a personagem do conteur torna-se um mito e representa, ao mesmo tempo, dupla função, a de dar voz ao grupo que escuta a narração de suas histórias orais, a compagnie-mésié-zé-dames, ${ }^{19}$ e, como já se disse, a de guardião das memórias. $\mathrm{O}$ escritor, que se constitui como seu herdeiro, não encontra, entretanto, a estabilidade característica do conteur, mas a duplicidade, tensões e contradições que não lhe garantem mais a expressão da totalidade da comunidade, nem a da palavra. Após Chronique des sept misères (1986), narrativa em que emergia um nous coletivo, as palavras das personagens se esfacelam. $\mathrm{O}$ narrador torna-se um je ou um nous ambíguo que, na falta de referentes fixos, se torna perplexo ante a complexidade das formações discursivas crioulas abundantes e abertas, e abre mão da enunciação única do conteur. A figura da compagnie é substituída pela do circo crioulo em Texaco (1992), onde se liberam fiç̧ões e o imaginário, revelando-se a poética do belo caótico, da reconstituição do belo caótico de Glissant, ou seja, a reconstituição dos universos caóticos em que se transformaram as sociedades contemporâneas, e uma ordem instável e imprevisível, em que o centro absorve as margens. Segundo Glissant, sua poética é

17 "Parnaso ultrapassado, simbolismo tardio e romantismo de segunda mão." (Tradução de nossa autoria)

18 "escavações arqueológicas"

19 "senhores-e-senhoras-da-companhia" a de que nada é mais belo que o caos - e não há nada de mais belo que o mundo caótico.

O belo caótico de Glissant é o que evidencia a falência do projeto ocidental de construção do ser uno, indivisível e transparente, estandardizado como ideal e responsável pela imobilização e submissão das sociedades periféricas. Do caos 
universal, que soterrou a maior das pretensões ocidentais - essa generalização do ser -, engendra-se uma dinâmica construtora do ser em movimento contínuo, do ser sendo, emergindo da sensibilidade difratada das humanidades. Segundo Glissant, isso é o que existe de mais apaixonante no mundo atual, na poética do mundo atual, estar na situação-limite de reconstituição dos universos caóticos.

A territorialização da identidade crioula referenda-se no mesmo campo de busca universal de realização da felicidade. A clivagem do sujeito crioulo determinada pelo conflito cultural manifesta-se forte em Manman Dlo contre la Fée Carabosse e em Chemin-d'École, historia-se em Chronique des sept misères e em Solibo Magnifique e é superada em Texaco. Na transcrição da crônica da comunidade de Texaco, escrita pela personagem MarieSophie Laborieux em cadernos, o escritor, que se define como marqueur de palavras, recolhe e transmite, em texto não linear, fragmentos de textos de Rabelais, Joyce, Faulkner, Glissant, entre muitos outros. Assim se configura o conceito de Crioulidade, que Chamoiseau metaforiza na identidade multilíngue, multirracial e multi-histórica de Texaco, definindo pátria como linguagem, como linguagens das línguas do mundo em dinâmica plural com todas as diversidades, caos onde o "imaginário invade o conceito", nas palavras de Glissant, como um afastamento, um desvio (ou uma deriva) do logos ocidental.

Na Biblioteca Schoelcher de Fort-de-France, onde se encontram (em um fingimento ficcional?) os cadernos de Marie-Sophie e as pastas do urbanista, pode-se ler, na de $n^{\circ} 17$, Folha XXV (do urbanista ao marqueur de paroles) o seguinte:

Au centre, une logique urbaine, occidentale, alignée, ordonnée, forte comme la langue française. De l'autre, le foisonnement ouvert de la langue créole dans la logique de Texaco. Mêlant ces deux langues, rêvant de toutes les langues, la ville créole parle en secret un langage neuf et ne craint plus Babel. ${ }^{20}$ (p. 243)

A inclusão da diferença, como projeto de uma poética do caos, da diversalidade, só se realizaria a partir da conquista de um lugar onde sua estrutura se tornasse visível. Entretanto, a

20 “No centro, uma lógica urbana, ocidental, alinhada, ordenada, forte como a língua francesa. Na margem, a abundância aberta da língua crioula na lógica de Texaco. Misturando essas duas línguas, sonhando com todas as línguas, a cidade crioula fala em segredo uma linguagem nova e não teme mais Babel". (Tradução de nossa autoria) modernidade e seus prolongamentos pós-modernos tendem a anular a diferença, apagando o lugar de sua produção e, portanto, de sua memória. A coleta e o registro dessa memória passam pela audiência atenta da palavra dos djobeurs (biscateiro) dos mercados da cidade de Fort-de-France, trabalho de campo do etnógrafo que justifica o marqueur familiarizado, incluído no espaço dos djobeurs para recolher cientificamente esse material e constatar a perda irrecuperável da alteridade cultural "ancorada" na oralidade. A visão etnográfica acrescenta um excesso à moda de Rabelais quando, morto Solibo Magnifique 
(provavelmente por uma "égorgette de la parole" uma asfixia, ou sufocação) seu "auditório" (sua compagnie-mésié-zé-dames) representa em festa, em carnavalização, o desaparecimento do Mestre, substituindo o som da garganta privilegiada pela algazarra da praça. A integração de todos os espaços, urbanos e emocionais, tem lugar em Texaco, onde Marie-Sophie, estruturada sua identidade, se domicializa em local proibido, lugar de estocagem de uma companhia petrolífera americana. Sua casa é o centro da resistência do bairro de Texaco contra o projeto racional de urbanização proposto pelo arquiteto ("Le Christ") que passa a ouvi-la e a respeitá-la como representante do bairro decidida a salvar Texaco da demolição e a erigir a Crioulidade em sua representação "diversal" como a espacialização ideal. A recusa do modelo codificado e racional do espaço urbano elege o espaço ordenado pela ocupação (des)ordenada do povo do En-ville (na periferia urbana). A deformação do conceito racional de espaço urbano pelo híbrido crioulo realiza a cidade ideal - "cet amas de fibrociment et de béton développait des vibrations bien nettes. Elles provenaient de loin, du concert de nos histoires" ${ }^{21}$ (1992, p. 423) - projeto da convivialidade erigida no Éloge de la Créolité (1989) como (ex)ótica transversal, estética produzida pelo marqueur:

Nous là, en bordage de l'En-ville, comme en bordage des bitations d'antan. Mais là, rien à prendre, il faut traverser, non pas pour ressortir de l'autre côté, mais pour l'élancer à travers, et bien garder le cap. Quel cap? Quitter la boue, toucher l'Homme, vivre la Terre entière. Tu as toutes les souches au cœur. ${ }^{22}$ (1992, p. 321)

(- Palavras do Mentô Totone (Mentor) registradas no Caderno no-27 de Marie-Sophie).

O encontro de Marie-Sophie com o Mentô, o "vieux-nègre de

21 "esta argamassa de concreto e betume desenvolvia vibrações bem claras. Elas provinham de longe, do concerto de nossas histórias". (Tradução de nossa autoria) 22 "Nós ali, na periferia do En-Ville, rondando a cidade, como no entorno das bitações de antigamente. Mas ali, nada a construir, é preciso atravessar, não para tornar a sair do outro lado, mas para se lançar através, e guardar bem o cabo. Que cabo? Deixar a lama, tocar o Homem, viver a Terra inteira. Você tem todas as fontes no coração." (Tradução de nossa autoria) 


\begin{abstract}
From the conflict between the western and creole logic, debates about the French language use, arise from French spoken countries writers. Patrick Chamoiseu discusses the theme in his work, where the poetic word appears as a "place" outside time and space, in which all the French languages are together.
\end{abstract}

Keywords: creolity; identity; writing; orality.

\title{
REFERÊNCIAS
}

APPIAH, Kwame Anthony. Na casa de meu pai: a África na filosofia da cultura. Rio de Janeiro: Contraponto, 1997.

BERNABÉ, Jean. Contribution à une approche glottocritique de l'espace antillais. In: La lingüistique, vol. 18, asc. 1, 1982.

BERNABÉ, Jean, CHAMOISEAU, Patrick, CONFIANT, Raphaël. Éloge de la créolité. Paris: Gallimard, 1989.

CHAMOISEAU, Patrick et CONFIANT, Raphaël. Lettres Créoles, tracées antillaises et continentales de la littérature. Martinique, Guyane, Guadeloupe, Haïti, 1635-1975. Paris: Hatier, 1991.

CHAMOISEAU, Patrick. Écrire en pays dominé. Paris: Gallimard, 1997.

. Chemin-d'école. Paris: Gallimard, 1994.

. Texaco. Paris: Gallimard, 1992.

. Solibo Magnifique. Paris: Gallimard, 1989.

. Chronique des Sept Misères. (Suivi de Paroles de Djobeurs,

Chutes et Notes et Préface de Édouard Glissant). Paris: Gallimard, 1986.

FRANÇA VIANNA, Magdala. Crioulização e Crioulidade. In: FIGUEIREDO, Eurídice (Org). Conceitos de Literatura e Cultura. Niterói RJ/Juiz de Fora MG: EdUFF/UFJF, 2005.

GLISSANT, Édouard. Introduction à une poétique du divers. Montréal: Les Presses de l’Université de Montréal, 1995. . Poétique de la relation. Paris: Seuil, 1990. . Le discours antillais. Paris: Seuil, 1981.

. Le Chaos-Monde, l'oral et l'écrit. In: LUDWIG, Ralph, POULLET, Hector, TELCHID, Sylviane. Écrire la parole de nuit. La nouvelle littérature antillaise. Paris: Gallimard, 1994. (Folio Essais, 239). 